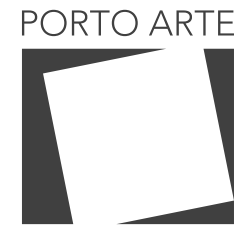

Revista de Artes Visuais

v. $25 n .43$

Jan/jun 2020 e-ISSN: 2179-8001

\title{
A crítica da curadoria, a curadoria crítica
}

The criticism of curatorship, the critical curatorship

\section{Bettina Rupp}

ORCID: 0000-0002-8187-3596

Portal da Universidade Federal do Rio Grande do Norte, Brasil

\section{Resumo}

Este artigo propõe analisar duas exposições pelo ponto de vista de suas curadorias e de críticas recebidas. Enquanto Aracy Amaral, curadora da mostra "Além fronteiras", da $8^{a}$ Bienal do Mercosul (Porto Alegre, 2011), recebia críticas pelo seu projeto curatorial; alguns anos mais tarde, a consagrada curadora publica uma crítica contundente relativa "À Nordeste" (São Paulo, 2019), exposição que teve como curadores Bitú Cassundé, Clarissa Diniz e Marcelo Campos. Serão confrontados argumentos que foram elaborados tanto para a realização das propostas curatoriais quanto de suas críticas, propondo uma reflexão sobre mudanças, nem sempre perceptíveis, que ocorrem na arte contemporânea.

Palavras-chave:

Curadoria. Crítica. Arte Contemporânea. Exposição.

\section{Abstract}

This paper proposes to analyze two exhibitions from the point of view of their curator-ships and criticisms received. While Aracy Amaral, curator of the "Além fronteiras" at the 8th Mercosul Biennial (Porto Alegre, 2011) was criticized for her curatorial project, a few years later, the consecrated curator published a overwhelming criticism regarding the "À Nordeste" (São Paulo, 2019), exhibition curated by Bitú Cassundé, Clarissa Diniz and Marcelo Campos. Arguments that were elaborated both for the realization of curatorial proposals and for their criticisms will be confronted, proposing a reflection on changes, not always noticeable, that occurin contemporary art.

Keywords

Curatorship. Criticism. Contemporary Art. Exhibition. 


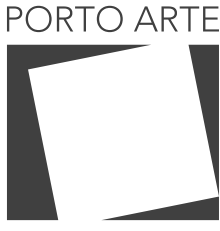

Revista de Artes Visuais

$\vee 25 n .43$

Jan/jun 2020

\section{Paisagens e fronteiras}

Em 2011, entre as sete mostras que compunham a $8^{a}$ Bienal do Mercosul "Ensaios de geopóetica", estava "Além fronteiras", com curadoria da historiadora e crítica de arte Aracy Amaral ${ }^{1}$. Em síntese, a mostra ocupou de forma organizada e espaçosa os dois andares da edificação centenária do MARGS². Estavam expostos trabalhos, a maioria instalações, de nove artistas vinculados à arte contemporânea que foram convidados a realizar produções comissionadas para a Bienal ou, ainda, apresentar um trabalho previamente existente adaptado ao novo espaço expositivo. 0 tema proposto por Amaral estava afinado às questões de territorialidade, geografia poética e cartográfica de acordo com o conceito sugerido pelo curador geral da mostra, José Roca. Mais especificamente, "Além fronteiras" perpassava relações entre paisagem e fronteira, aspectos geográficos e culturais, crenças e povos originários pertencentes a três regiões diferentes do Rio Grande do Sul.

0 mote sugerido aos artistas foi que de alguma maneira cada um escolhesse entre a verticalidade abrupta dos cânions, a horizontalidade ondulada dos Pampas e a presença jesuítica das Missões, sendo que estas regiões possuem aspectos geográficos que ultrapassam as fronteiras do estado, no primeiro caso, ou atingem também países vizinhos como Argentina, Paraguai e Uruguai. São regiões que não se limitam a linhas demarcadas nos mapas. Os artistas brasileiros Cao Guimarães (1965), Carlos Pasquetti (1948), Carlos Vergara (1941), Felipe Cohen (1976), Lucia Koch (1966) e Marina Camargo (1980), além dos convidados estrangeiros Gal Weinstein (1970, Israel), Irene Kopelman (1974, Argentina) e Jose Alejandro Restrepo (1959, França), se engajaram na proposta lançada por Amaral apresentando trabalhos afinados ao mote sugerido, sendo que a maioria realizou essa aproximação com a curadoria de forma evidenciada.

Coube a Pasquetti uma postura mais anárquica, como seria esperado do artista, pois ele trouxe uma interpretação do conceito de paisagem muito peculiar. Ele propôs ao visitante um diálogo em uma linguagem cifrada, talvez indecifrável, mas, ao mesmo tempo, próxima e que gerava indagações nos visitantes: "O que é isso?", e respostas dos mediadores como "Isso é NINAYROSA", "E o que é NINAYROSA?", "O quê você acha que pode ser?", gerando uma conversa divertida e muitas vezes nonsense sobre o que seria arte contemporânea. Outros dois trabalhos, Espaço para esconderijo (1972) e Diálogos Silenciosos (1974/1975), remetiam a um período político de censura à arte, cultura e formas individuais de expressão.

\footnotetext{
1- Aracy A. Amaral (1930) é crítica de arte, curadora, historiadora de arte e arquitetura. Professora titular em Historia da Arte da Faculdade de Arquitetura e Urbanismo, Universidade de São Paulo. Foi diretora da Pinacoteca do Estado de São Paulo e do Museu de Arte Contemporânea da Universidade de São Paulo. Curadora de diversas exposições no Brasil e América Latina, membro do Comitê Internacional de Premiação do Prince Claus Fund (Haia/Holanda) entre 2002 e 2005, e coordenadora do projeto Rumos do Itaú Cultural, de 2005 a 2006. Em 2009, foi curadora de exposição na Trienal de Santiago, Chile. Recebeu o John Simon Guggenheim Fellowship, entre outros prêmios, e é autora de inúmeros livros publicados sobre o modernismo no Brasil, arte latino-americana e arte contemporânea brasileira, além de ter organizado antologias sobre arte brasileira e da América Latina. 


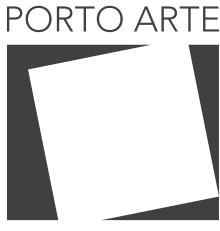

Revista de Artes Visuais

$\vee 25 n .43$ Jan/jun 2020 e-ISSN: 2179-8001

Podemos dizer que a exposição atingiu o objetivo lançado pela curadora por dois aspectos. 0 primeiro, é que havia sintonia entre as paisagens naturais propostas pela curadoria e as apresentações dos artistas. Nas palavras de Amaral (2011, p. 430), houve a intenção de lançar um "[...] pensamento norteador para o espaço expositivo do MARGS" e para isso foram lançadas "[...] três rotas dentro do Rio Grande do Sul que, a nosso ver, propiciam visões diferenciadas e férteis a interpretações". A curadora comenta sobre esse propósito no catálogo:

\footnotetext{
O desafio para os artistas convidados para "Além fronteiras" foi a opção que deveriam fazer por uma dessas três regiões: os pampas, a região das antigas Missões e a região dos canyons. E, dessa escolha deveriam extrair para suas presenças na $8^{a}$ Bienal uma interpretação visual que registrasse sua poética frente a uma vivência dessas realidades físico-culturais (Amaral, 2011, p. 431).
}

Alguns dos artistas viajaram pelas regiões sugeridas e/ou propuseram interpretações geográficas próximas do conceito de paisagem, como Camargo, Cohen e Kopelman.

o resultado dessa cartografia que atravessou o Estado trouxe produções muito interessantes e poéticas. A exposição nos transmitia um ar melancólico em certos momentos, como nos vídeos de Guimarães, que apresentavam brinquedos de praças públicas feitos com materiais alternativos, mas desgastados pelo tempo, ou como na projeção em vídeo de Koch, que trazia a lembrança lúdica de uma fonte com espetáculo de luzes coloridas presente em uma cidade do interior que foi reativada especialmente para a mostra.

Enquanto em "Geopoéticas", que ocupou três armazéns do cais do porto, a territorialidade era colocada em questão em muitos dos trabalhos, no MARGS, a conquista desses territórios insinuou que não houve conflitos e nem maiores desconfortos, como se não houvesse disputas territoriais na ocupação dessas regiões. Nem mesmo quando apresentou o projeto de dois artistas, Vergara e Weinstein, que exploraram a herança deixada pelos jesuítas nas Missões. Pode-se dizer que a instalação de Restrepo é a que possuía um teor mais crítico quanto aos impactos da permanência jesuítica sobre as culturas indígenas locais.

O segundo aspecto diz respeito a expografia da mostra, pois podemos dizer que para esta curadoria, o projeto expográfico foi determinante. A intenção foi apresentar a produção de cada artista convidado separada dos outros, como em territórios devidamente demarcados no mapa. Isto porque as instalações, projeções de vídeos, desenhos, fotos ou objetos estavam expostos em salas individuais, ou seja, cada artista apresentou seus projetos em um amplo espaço dividido por paredes que estabeleciam um sentido de início e fim a cada nicho expositivo. Sem dúvida, os artistas ocuparam seu "territórios" físicos, sem ultrapassar as fronteiras com as terras vizinhas. 0 projeto de expografia teve uma apresentação moderna, seguindo a tendência do "cubo branco" (O'Doherty, 2002), em que muitos detalhes arquitetônicos da edificação do museu fo- 


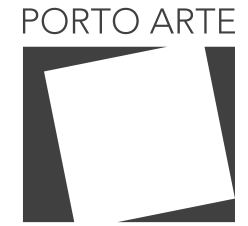

Revista de Artes Visuais

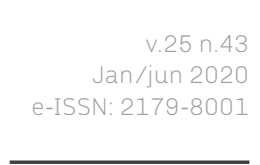

Figura 1: Espaço expositivo de Marina Camargo, Tratado de limites, vista da instalação. Foto: Fabio del Re. Fonte: <https:// www.marinacamargo.com/wpcontent/uploads/2014/10/

Trat-Limites_MarinaCamargo_ bienal-mercosul_Foto_

FabioDelRe_2011-371.jpg> Acesso em: 13 jun. 2020 ram escondidos por paredes pintadas de tons claros e neutros. 0 visitante sabia quando terminava o espaço de um artista e começava o de outro (fig. 01). Afinal, como falar de fronteiras sem traçar territórios?

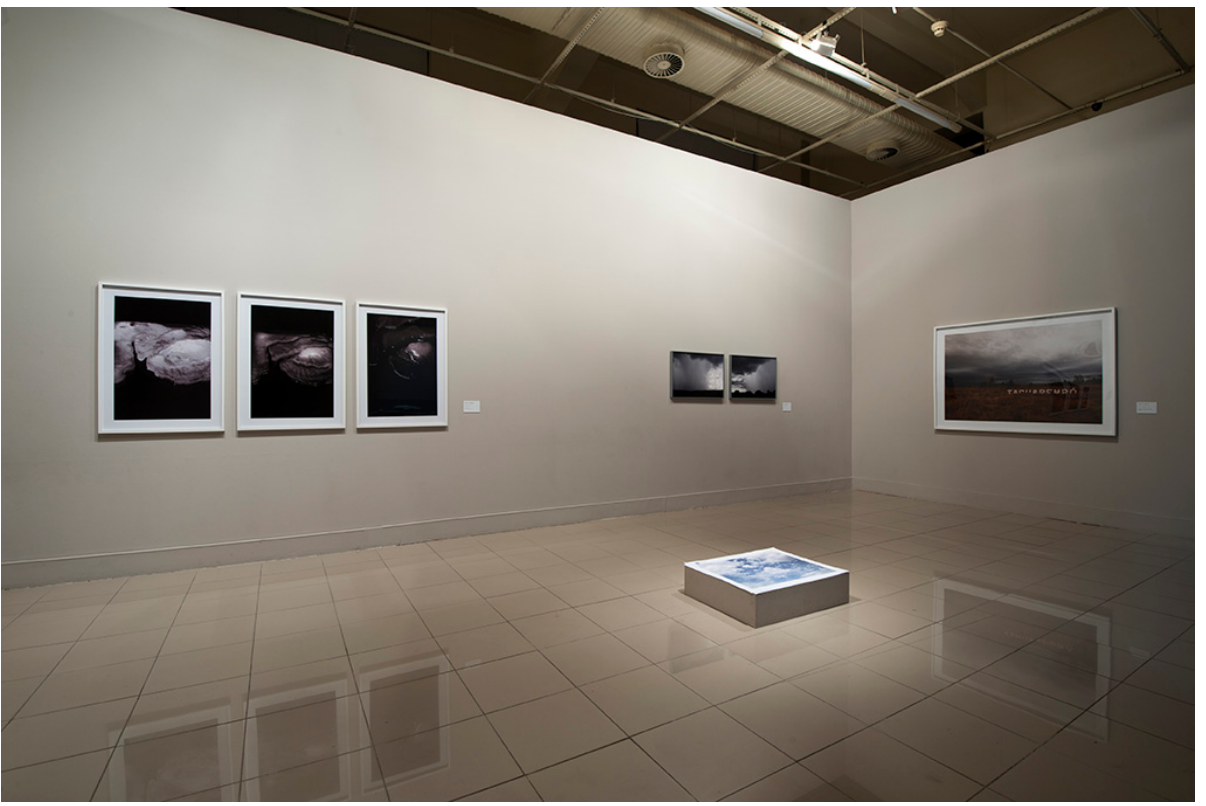

Estes aspectos citados deram à exposição uma sensação de paisagem, como se quase tudo ali estivesse sendo observado de longe. Não por acaso, a proibição de tocar em certos objetos "tocáveis" - a exemplo da grande onça de Vergara produzida em fibra de vidro, que imitava um pequeno bicho guarani esculpido em madeira, como o monte de feno seco e os veludos de Pasquetti, o santo na sala escura de Restrepo, as falsas sombras das caixas de papelão de Cohen e o imenso carpete de Weinstein formado por retalhos que imitavam plantações vistas de um satélite - gerava uma tentação frustrada nos visitantes. Especificamente este último, Entre-Ijuís, foi o que mais distanciava o visitante da instalação e aproximava ao sentido de paisagem, muitas vezes uma extensa área de terra da qual não podemos ultrapassar os limites da cerca.

Mas o público sabe que "não pode tocar" ou "pisar nas obras", e certamente não foi isto que causou alguns comentários curiosos vindos de críticos e curadores sobre o que estava acontecendo naquela exposição ao circularem pelas salas ${ }^{3}$. Muitos desses questionamentos informais não foram organizados em resenhas, mas certamente ocorreram porque Amaral contaminou o "sagrado" espaço destinado à expor arte contemporânea com peças históricas de museus locais.

No intuito de complementar seu projeto curatorial, ela explica que a dúzia de documentos e objetos históricos funcionariam como um contraponto "[...] de outras

\footnotetext{
3- É preciso esclarecer que esses comentários ficaram registrados na memória, uma vez que a autora
} atuou como mediadora da mostra. 


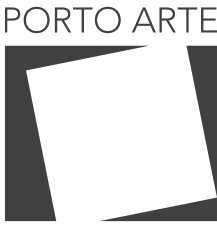

Revista de Artes Visuais

$\vee 25 n .43$

Jan/jun 2020 e-ISSN: 2179-8001

gerações" (Amaral, 2011, p. 432) distribuídos no espaço expositivo ${ }^{4}$. Peças e documentos como um mapa das Missões Jesuíticas de 1749, um zoólito em formato de tubarão com cerca de três mil anos ${ }^{5}$, um aquecedor de leito do início do século $X X$, uma gargalheira para uso em escravos do séc. XVIII, uma máquina de escrever muito antiga e mais algumas pinturas, aquarelas e gravuras de artistas dos séculos XIX e XX. Entre estas, uma paisagem de Iberê Camargo e uma cena de campo com colonizadores europeus em pintura de Pedro Weingärtner.

Evidentemente que essas peças não tinham relação temporal com as produções dos artistas contemporâneos, e algumas não tinham uma relação de conteúdo evidente, mas suscitavam aproximações com os locais geográficos e os resquícios de outros povos que habitaram aqueles mesmos lugares. Esse anacronismo proposital foi o aspecto mais interessante da proposta curatorial. Foram esses objetos que suscitaram um pensar "além fronteiras" espaço-temporal. Aliás, foram esses "objetos" calejados de história que trouxeram uma presença mais humana à exposição. Era como se alguns artistas tivessem trazido a sua percepção das paisagens visitadas e deslocadas para o museu, e a curadora trouxesse os resquícios humanos daqueles que as colonizaram antes. Enfim, um conceito complexo de exposição, que exigia mais interpretações por parte do público visitante, do que uma simples "circulada" para ver as obras de arte contemporânea e imaginar relações entre elas.

Nesse sentido, era compreensível que a proposta de Amaral tivesse soado para muitos como algo estranho, uma vez que uma grande parte das exposições com foco na arte contemporânea ainda segue um recorte temporal relacionado a um curto período de tempo (atual). No entanto, ficou visível que a exposição planejada pela curadora queria que os trabalhos dos artistas convidados dialogassem, posteriormente, com artefatos ou obras de outros artistas, a maioria já falecidos, incluídos na mostra. Isso sugere que ela intencionou apresentar um "partido", ou seja, uma proposta cuidadosamente elaborada, interligando tempos históricos distintos.

A proposta curatorial estava clara e foi elegantemente realizada, tanto pelos artistas quanto pela equipe da expografia. As regiões geográficas foram interpretadas pelos artistas, a equipe que projetou o espaço expositivo organizou o museu em "territórios" e a curadora promoveu um pensar além do tempo e do espaço, um pensar "além fronteiras".

Porém, podemos questionar outros aspectos relativos à mostra, como a ausência daqueles que foram colonizados à força de violência, que foram extraídos de uma outra terra e tiveram seus corpos explorados, daqueles que perderam o nome e ganharam um sobrenome genérico português, daqueles que perderam sua língua, sua fala e sua natureza. Por algum motivo essas questões não entraram de forma mais efetiva na exposição, mas

\footnotetext{
4- É importante citar que um dos documentos históricos citados pela curadora era da artista Lenir de Miranda (1945), "All-in com a história de um (n² 2 da série 'Autografada de todos nós')", 1993, técnica mista 18 páginas, que curiosamente compunha a série, mesmo se tratando de uma obra de arte contemporânea. 5- Amaral deve ter ficado muito impactada com o alto poder de síntese contido nas formas dos zoólitos peças esculpidas em pedra e encontradas em sambaquis principalmente em Santa Catarina e Rio Grande do Sul, aos quais decidiu retornar quando foi convidada para ser curadora do $34^{\circ}$ Panorama da Arte Brasileira, no MAM-SP, em 2015, em conjunto com Paulo Miyada, dando o devido destaque e contextualização histórica aos objetos.
} 


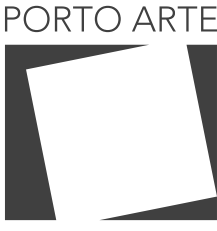

Revista de Artes Visuais

$\vee 25 n .43$

Jan/jun 2020 e-ISSN: 2179-8001

estavam incubadas naqueles objetos históricos. Desde o zoólito que reivindicava uma existência ancestral dos povos originários das Américas, que habitaram aos milhares essas terras, até o silêncio do escravo oprimido que carregava a gargalheira de ferro no pescoço.

De qualquer modo, entre a $8^{a}$ Bienal do Mercosul e a exposição "À nordeste" (2019), que ocorreu no Sesc da 24 de maio em São Paulo, ocorreram manifestações e mudanças no cenário político que evidenciaram diversos conflitos inerentes ao sentido de território brasileiro e disputas pelo poder. Se por um lado nos galpões do cais, no ambiente micro, se questionavam, conceitos como nação e território, nacionalismo e poder, fronteira e migração, democracia e república, raça e questão indígena, conflito e discursos ideológicos (Roca, 2011); por outro lado, pequenos movimentos, inicialmente esparsos e sinceros, se aglutinaram em torno de ideais comuns motivados por jovens que formularam alguns jargões como: "Não é por vinte centavos" e "Não vai ter copa". Jovens que estavam interligados por banda larga e que começaram a assistir outros canais de comunicação que não os da TV aberta, entre eles Mídia Ninja; mas que, principalmente, estavam interessados em dialogar e propor mudanças que beneficiassem mais setores da sociedade, sobretudo aqueles que ainda viviam à margem dos bens públicos. Independentemente dos rumos que se seguiram e os desvios das causas dos movimentos horizontalizados, posteriormente promovidos por oportunistas, o fato é que o conjunto de ações abalou a estrutura da política vigente.

Após o resultado das eleições de 2014 , começaram a circular na internet comentários preconceituosos e xenófobos destinados aos nordestinos, sugerindo que eles eram responsáveis pela reeleição da legenda Dilma Rousseff e Michel Temer $(51,64 \%)$ contra a legenda Aécio Neves e Aloysio Nunes (48,36\%), uma vez que a primeira foi vencedora na totalidade dos estados do Nordeste. 0 que não quer dizer que esse dado representasse o acumulado do número de votos. Isso porque a soma da população dos estados do Sul (14\%) e Sudeste (42\%) é bem maior do que a do Nordeste (28\%), ainda que se inclua a região Norte (9\%) no cálculo. No entanto, imagens do mapa de um país dividido pelas cores vermeIho (Rousseff-Temer) abrangendo Norte e Nordeste e azul (Neves-Nunes) nas regiões Sudeste e Sul deram margem para interpretações superficiais sobre o resultado das eleições. $E$ isso foi apenas o começo de uma série de difamações preconceituosas que se seguiram.

Nordestinos retratados em filmes de substanciosa bilheteria como Que horas ela volta? (2015), com roteiro e direção de Anna Muylaert, no qual a filha de uma empregada doméstica, pernambucana, consegue entrar na universidade pública, e um jovem filho de um casal paulistano, contratante da empregada, não consegue, causou um efeito de mal estar velado entre muitas famílias de classe média que assistiram ao filme. "Nordestinos", não apenas, mas diversas classes sociais que tiveram seu poder aquisitivo ampliado durante os anos 2000, principalmente a partir da estabilidade econômica, das políticas públicas de inclusão social e redução de impostos para aquisição de bens materiais, passaram a poder usufruir de serviços e bens de consumo antes inimagináveis, que iam de máquinas de lavar roupa a veículos, citando apenas alguns exemplos.

O conjunto de mudanças sociais acirrou um preconceito que já existia contra aqueles migrantes que saíram do Nordeste a partir da década de 1960 para levantar prédios, zelar portarias, proteger ruas, cuidar de crianças, alimentar famílias, diri- 


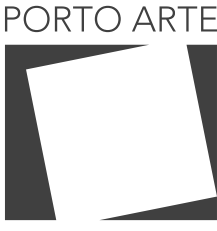

Revista de Artes Visuais

v. 25 n. 43

Jan/jun 2020 e-ISSN: 2179-8001

gir táxis e preparar o café dos paulistas. Mais do que nunca, neste período, isso ficou aflorado e se associou a um movimento político muito bem articulado que eclodiu no processo de impeachment da presidenta ${ }^{6}$, em 2016, assumindo o governo, seu vice.

\section{Entre tantos nordestes}

Em 16 de maio de 2019, o novo Sesc da 24 de Maio, situado na região central da capital paulista e inaugurado em 2017, após uma longa reforma que teve projeto assinado pelo arquiteto Paulo Mendes da Rocha, apresentou ao público "À Nordeste". A exposição contava com mais de 275 trabalhos de 160 artistas, coletivos ou associações de artistas, que nasceram, vivem ou decidiram viver na região Nordeste. 0 projeto curatorial foi pensado por Bitú Cassundé7, curador do Museu de Arte Contemporânea do Ceará, Clarissa Diniz ${ }^{8}$, crítica de arte, curadora e professora na Escola de Artes Visuais do Parque Lage, e Marcelo Campos $^{9}$, curador e professor na UERJ.

De acordo com os curadores, o ponto de partida da exposição foi um texto de Yuri Firmeza (1982), escrito em 2011, que lançava a questão: "A Nordeste de que?", e que fora republicado no catálogo da mostra. Nele, Firmeza propõe refletir sobre como lidar com as instâncias de intolerância ao outro, seja por situação geográfica, colonial, conduta sexual ou definição de gênero. Segue um trecho com outras indagações do artista:

\footnotetext{
Como produzir deslocamentos nos discursos heteronormativos, de dentro do dispositivo da sexualidade? Será que alguns artistas "nordestinos" não desmoronam pilares identitários e deslocam, cada qual a seu modo, a representação colonial que o sudeste insiste em reificar do Nordeste? Não corresponderia ao colonialismo interno a obliteração histórica? (Firmeza, 2020)
}

\footnotetext{
6- Os fatos aqui citados estão descritos de forma bastante sucinta, pois não é a intenção do artigo aprofundar os meandros políticos e econômicos que ocorreram na década de 2010, apenas orientar a leitura para a situação do contexto do período. Há vasta literatura a respeito, com maior número de dados e informações. 7- Bitu Cassundé é mestre pela Escola de Belas Artes da Universidade Federal de Minas Gerais. De 1998 a 2007, foi curador assistente e coordenador de pesquisa no Museu de Arte Contemporânea do Ceará, integrou a equipe curatorial do Programa Rumos Artes Visuais do Itaú Cultural, em São Paulo, e dirigiu o Museu Murillo La Greca, em Recife. Dentre os destaques de seus projetos curatoriais estão: "Leonilson - Sob o peso dos meus amores", no Itaú Cultural, em 2011, e "Metrô de superfície II", no Centro Cultural São Paulo, em 2013. Com Clarissa Diniz, formou a coleção contemporânea do Centro Cultural Banco do Nordeste, vinculado ao projeto "Metrô de superfície". Atualmente, é curador do Museu de Arte Contemporânea do Ceará e coordenador do Laboratório de Artes Visuais do Porto Iracema das Artes, em Fortaleza.

8-Clarissa Diniz (1985) é mestre pelo Programa de Pós-Graduação em Artes da Universidade do Estado do Rio de Janeiro e doutoranda do Programa de Pós-Graduação em Sociologia e Antropologia da Universidade Federal do Rio de Janeiro. Com Cayo Honorato, Orlando Maneschy e Paulo Herkenhoff, publicou o título "Contrapensamento selvagem". Realizou curadorias de importantes mostras pelo Nordeste e Sudeste, entre as quais destacam-se "Ambiguações", no Centro Cultural Banco do Brasil, Rio de Janeiro, e "Pernambuco experimental", no Museu de Arte do Rio (MAR), ambas em 2013. Clarissa também é crítica de arte e foi editora da Tatuí, revista de crítica de arte, entre 2006 e 2015. Atualmente é professora na Escola de Artes Visuais do Parque Lage.

9- Marcelo Campos é doutor em Artes Visuais pela Escola de Belas Artes da UFRJ (EBA-UFRJ), professor e coordenador de graduação no Instituto de Artes da UERJ e da Escola de Artes Visuais do Parque Lage (EAV - Parque Lage). Tem textos publicados em periódicos e catálogos nacionais e internacionais. Dentre seus projetos curatoriais, estão "Faustus", de José Rufino, Palácio da Aclamação, em Salvador, em 2009; “E agora toda terra é barro", de Brígida Baltar, Centro Cultural Banco do Nordeste, em Cariri e Fortaleza, entre 2008 e 2009; "Sertão contemporâneo", Caixa Cultural RJ e Salvador, entre 2008 e 2009.
} 


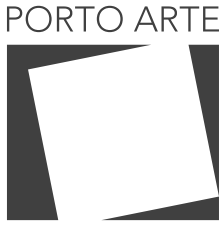

Revista de Artes Visuais

$\vee 25 n .43$ Jan/jun 2020 e-ISSN: 2179-8001

Ao mesmo tempo em que há uma necessidade de revisão histórica pelas inúmeras injustiças ocorridas àqueles que pensam ou decidem ser diferentes dos padrões sociais estabelecidos como "aceitos", por outro lado, não se pode perder de vista a subjetividade individual.

Desse modo, atribuir o termo "nordestino" como sendo específico de uma única categoria identitária que engloba uma série de indivíduos é cair em uma armadilha, que, quando não beira à folclorização, pode gerar preconceitos. Nesse sentido, os curadores decidiram utilizar a crase e não o artigo masculino "o" diante da palavra "nordeste", ressaltando uma situação mais do que uma região definida no mapa. A decisão pontual é explicada por Clarissa Diniz em reportagem à redação da Revista e:

Com esse conjunto riquíssimo, diverso e heterogêneo de obras e artistas, não temos qualquer pretensão em apresentar ao público o que é o Nordeste hoje, mas, sim, o que é estar à Nordeste. Falamos aqui de uma posição (e seus constantes reposicionamentos) e não de identidade. Sob essa perspectiva, lançamos luz sobre jogos políticos e estéticos, marcados por contraposições em relações às hegemonias, centralidades e, inclusive, outras periferias, em suas mais variadas acepções (Reflexão..., 2020).

Mais do que fugir da seca, imaginário recorrente da questão da mobilidade do Nordeste para o Sudeste, havia outras transformações que estavam em andamento na região, como o declínio dos engenhos de cana-de-açúcar e a industrialização de processos agrícolas eliminando mão de obra nas lavouras. 0 diretor do Sesc São Paulo, Danilo Santos de Miranda, informa no catálogo digital da mostra que:

[...] é fundamental conhecer os aspectos contextuais que corroboraram a formação de uma localidade, contribuindo para o entendimento das referências presentes em seu cotidiano. [...] Suas produções, realizadas em certa região e período histórico, portam em si potencialmente, características reveladoras das condições sociais, econômicas, políticas e culturais que convergiram para a sua elaboração. [...] A presença nordestina extrapola as delimitações de seu território. (Miranda, 2020)

Campos em reportagem sobre a exposição na Revista e complementa ainda que as políticas socioculturais de cotas promoveram acesso de estudantes às universidades e modificaram a mobilidade dos jovens da região "[...] repensando a ferida colonial ainda aberta, protagonizando o contingente negro, inclusive nas artes visuais" (Outras..., 2019, p. 30), e isto trouxe efeitos imediatos que precisavam constar na exposição, por exemplo, a apresentação de fotografias da dupla Kaick \& Allan, formada por Alisson Kaick Rodrigues Freitas (1994) e Allan Conceição da Silva (1994), alunos do cur- 


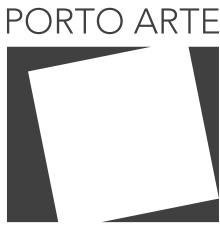

Revista de Artes Visuais

Figura 2: "À Nordeste", vista geral da exposição com vídeo de Ayrson Heráclito; série Pau bonito, de Cristiano Lenhardt; acima fotografias de Gê Viana, da série Paridade, e de Márcio Vasconcelos à direita. Foto: Imagem cortesia Sesc 24 de maio. Fonte: <https: // terremoto.mx/wp-content/ uploads/2019/08/nordesteimagem-geral_47996028078_o jpg>Acesso em: 13 jun. 2020 so de Artes Visuais da UFRB. Além da dupla, houve a inclusão de artistas que apresentaram temáticas sobre a população negra, seus discursos, culturas, religiosidade ou problemas enfrentados em diversas situações cotidianas na mostra. Entre eles, Ayrson Heráclito (1968), Pedro Marighella (1979), Ton Bezerra (1977) e Tiago Sant'Ana (1990).

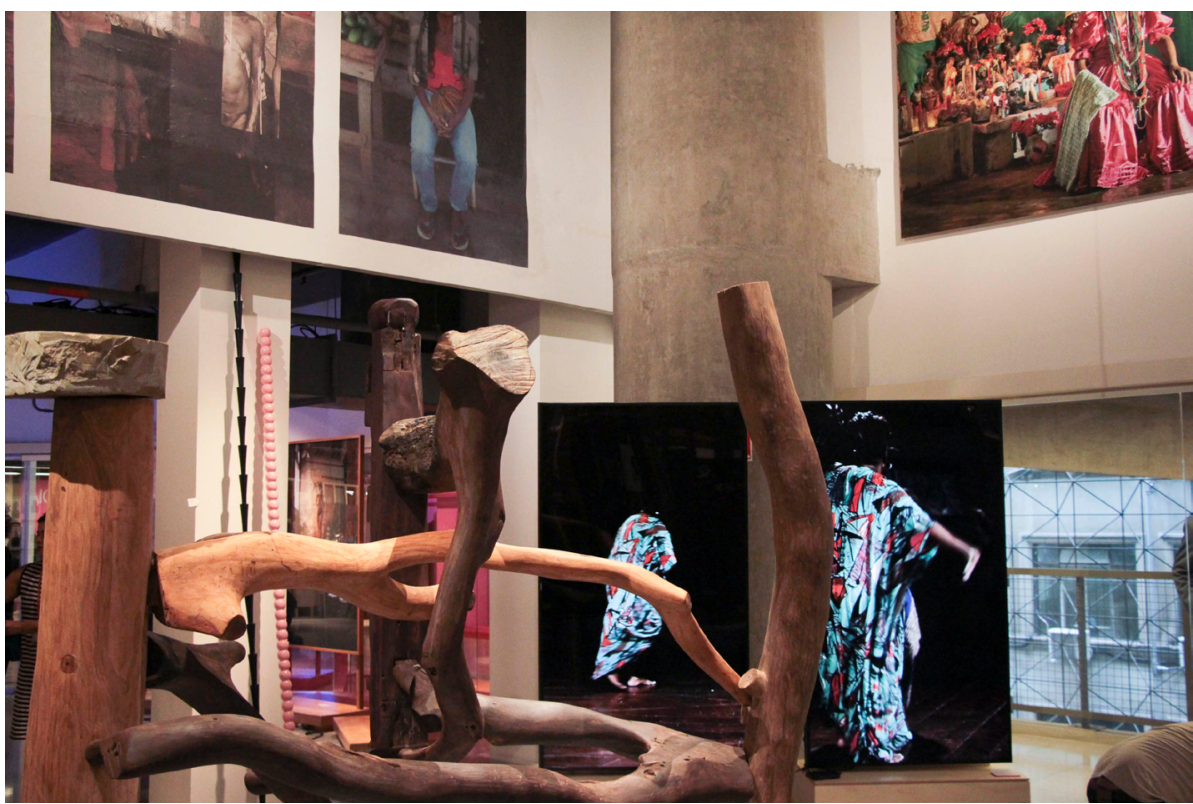

O fato de a mostra abrigar muitas vozes e, portanto, povoar o espaço expositivo de modo abundante, para alguns críticos de modo excessivo ou "saturado" (Amaral, 2020; Chiarelli, 2020), indica que o objetivo da curadoria era abrigar a pluralidade das diferentes maneiras de viver e sentir uma região, situação, posição, um lugar no mundo, não se fechando para este ou aquele grupo que poderia representar ou sintetizar as ideias de um conjunto de artistas reunidos em torno de uma causa em comum (fig. 02).

Além da pluralidade de vozes, por outro lado, temos que compreender que quando circulamos em feiras, entre bancas de mercados públicos, em meio a lojas de artesanato e barracas de comércio informal, temos a sensação de que nesses lugares todos estão chamando a nossa atenção ao mesmo tempo. Quem já teve essa experiência sabe que nas feiras a céu aberto do Nordeste há uma profusão de acontecimentos, sons, cheiros, conversas, música, gritos de animais, insetos, ou seja, não há uma hierarquia do que é mais importante, não há um mestre de cerimônias que organizará um circuito de acontecimentos aos visitantes. Quem vai à feira precisará encontrar aquilo que procura tanto quanto ser encontrado por aquilo que nem procurava.

No caso de "À Nordeste", quem chegava logo era absorvido por esse torvelinho, não só de trabalhos de artistas, como também pelo público circulante, pois alguns corredores, às vezes, ficavam estreitos pelo volume de pessoas. Idêntico ao que acontece nesses lugares descritos anteriormente. 
Figura 3: Almandrade, Sem título (2015), madeira pintada, e Sente-se (1983), madeira e corda Exposição "À Nordeste". Foto: Arquivo da autora

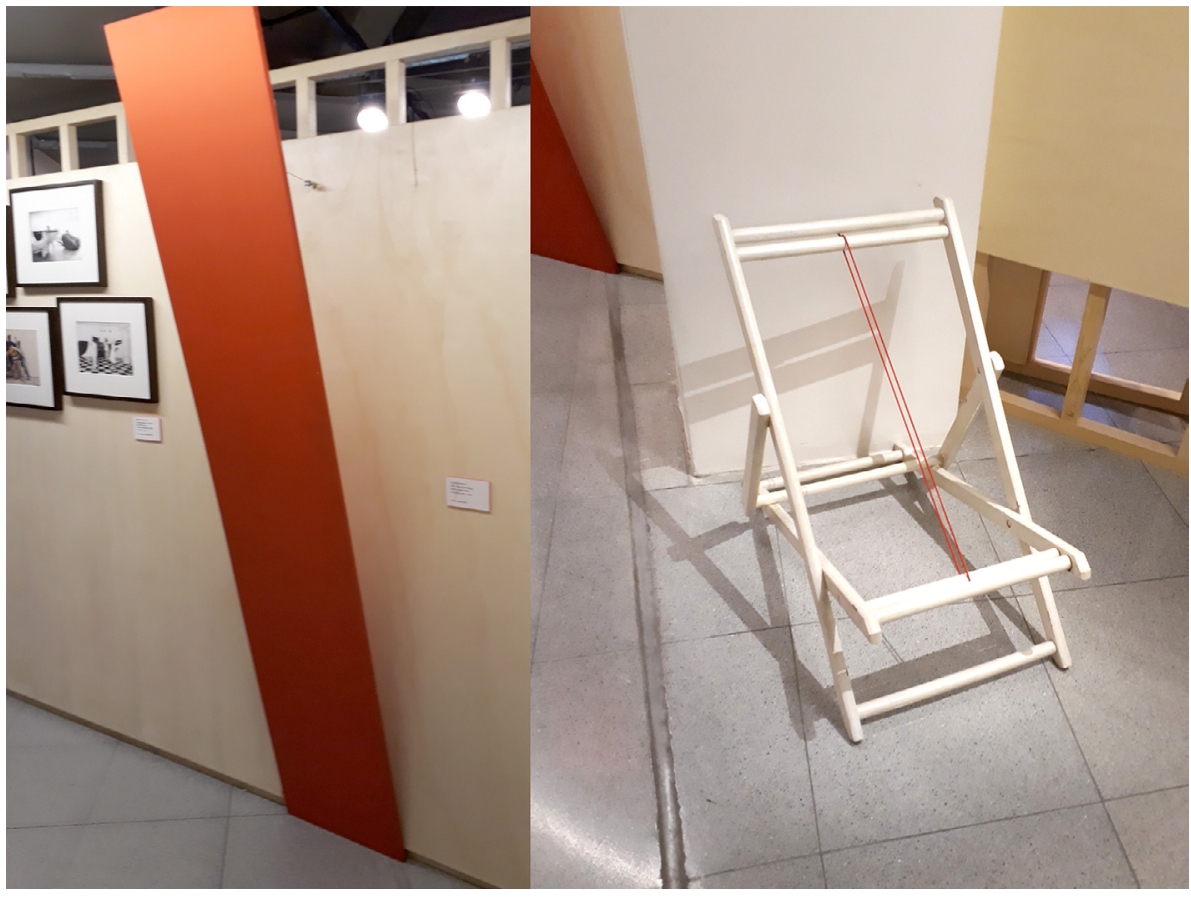

Assim como na feira algo que nos interessa pode estar escondido, também nesta exposição alguns trabalhos de artistas estavam camuflados ao lado de outros. É verdade que quase esbarramos na madeira vermelha que sai da parede, obra minimalista de Almandrade (1953), Sem título (1979/1988/2015), ou em sua falsa espreguiçadeira Sente-se (1983) que concentra um único fio vermelho, provavelmente um elástico, na cadeira de praia feita em madeira (fig. 03). Impossível não ver e admirar o poder de síntese do artista.

Por outro lado, talvez nem todos repararam que, além do vídeo Polvorosa (2012) e das litogravuras da série Vermelho (2014) de Cristiano Lenhardt (1975) também estavam dispostos no espaço uma série chamada Pau bonito (2015). A série reúne sarrafos de madeira esculpidos com repetições modulares que, devido às cores e ao formato, remetem há algo que já vimos, mas não temos muita certeza quando e onde, pois poderiam ser colunas torneadas de móveis antigos com cores inusitadas ou algum item de circo que estava por ali, encostado em algum pilar. Outro trabalho que encontrava-se discreto no ambiente era Extravio ameríndio (2014-2017), de Carlos Mélo (1969), um néon colocado em uma parede mais afastada no qual piscavam palavras que usam as mesmas letras: "Iracema", "America", e quem sabe ainda outras leituras possíveis como "America Rica" e "Ira de Iracema"? (fig. 04)

Além destes, alguns trabalhos faziam uma conexão imediata com os de outros artistas da mostra. Um exemplo é a série documental Edifício Recife (2013), de Bárbara Wagner (1980) e Benjamin de Burca (1975). O conjunto de fotografias e depoimentos aborda de modo explícito a lei de Recife (PE) que obriga incorporadoras e condomínios 


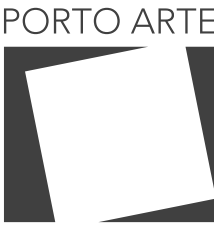

Revista de Artes Visuais

v. $25 n .43$ Jan/jun 2020 e-ISSN: 2179-8001
Figura 4: Carlos Mélo, Extravio ameríndio (2014-2017) instalação, neon, $31 \times 180 \times 18$ cm, exposição "A nordeste". Foto: Arquivo da autora a instalar obras de arte nos jardins ou entradas de edifícios, a partir de determinada metragem quadrada, e isto acaba criando uma relação inusitada entre essas obras e a percepção que os porteiros têm delas. Essa série remete a uma instalação que estava na XXIV Bienal de São Paulo (1998), onde se apertava botões de porteiros eletrônicos instalados em uma grande parede e se escutava depoimentos de porteiros que migraram do Nordeste para trabalhar em São Paulo. Esta instalação, de Dias (1964) e Riedweg (1955), Os Raimundos, os Severinos e os Franciscos (1998) estava presente na exposição, só que em um formato um pouco diferente do original. Embora haja uma analogia entre um trabalho e outro, é interessante vê-los juntos nesta exposição e perceber que, passados 15 anos entre uma e outra, certas questões permanecem as mes-

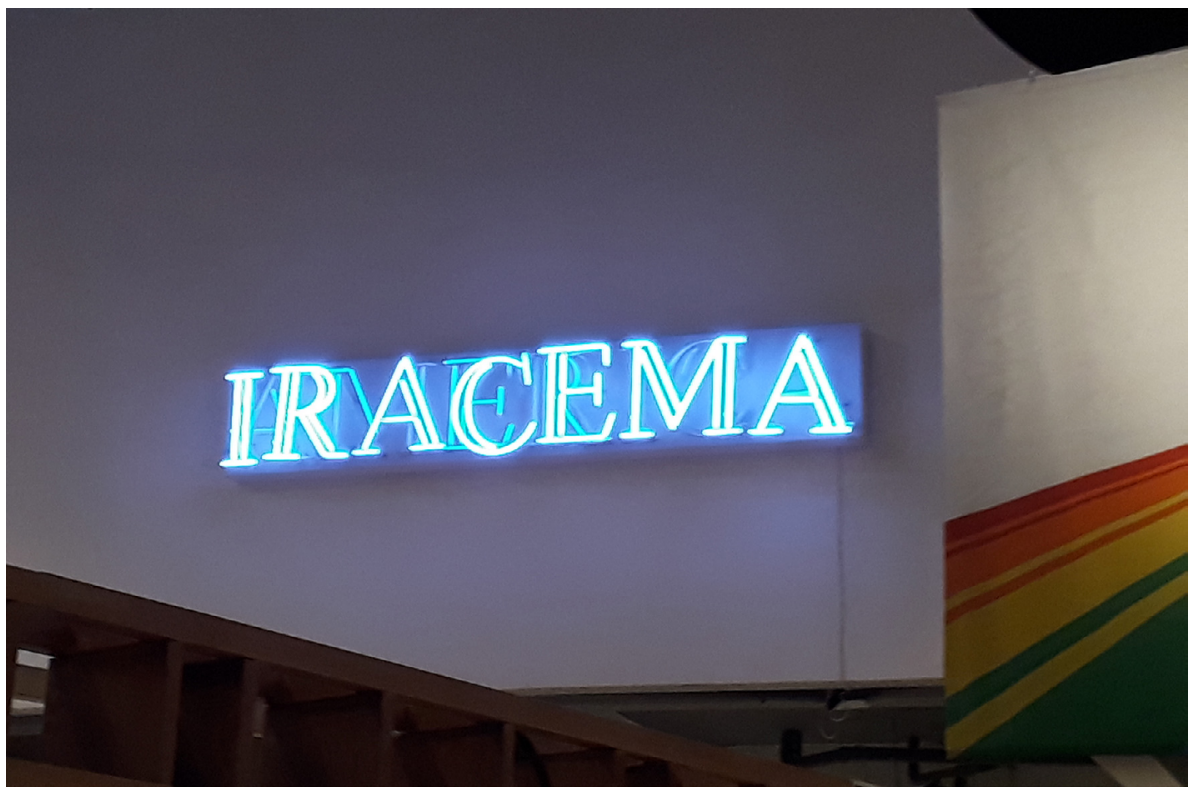

mas, ou seja, os processos de invisibilidade social continuam operantes na sociedade.

Ainda sobre esta questão, o documentário Doméstica (2012), de Gabriel Mascaro (1983), expõe de modo cru e sem temperos como estes processos atuam sobre as empregadas e a ausência histórica de seus direitos trabalhistas. Direitos conquistados após longas lutas e em via de se perder na esquina de um processo de "pejotização". 0 filme de 75 minutos, que apresenta sete narrativas de mulheres e um homem que trabalham em serviços de limpeza e cuidados da casa, estava dividido em sete partes nos quatro monitores. Infelizmente, não havia um banco ou cadeiras para acomodar aqueles que quisessem assisti-lo na íntegra.

Outro vídeo bem mais curto e com temática próxima, embora com um visual quase nonsense, era Saída da fábrica Cione (2015), de Virgínia Pinho (1985). Entre a simplicidade das imagens e a multiplicação das trabalhadoras uniformizadas saindo da fábrica, como uma esteira que jorra seus produtos, ficamos hipnotizados pela cena, pensando quem são aquelas mulheres, onde vivem, o que pensam e o que fazem naquela fábrica? 


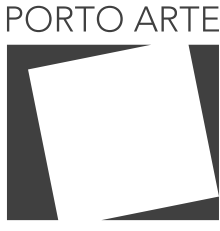

Revista de Artes Visuais

$\vee 25 n .43$

Jan/jun 2020 e-ISSN: 2179-8001

É preciso citar um aspecto que não estava tão visível na mostra, mas aqueles que olharam com mais calma devem ter percebido: a presença de artistas mulheres ainda pouco conhecidas ou valorizadas fora do circuito artístico local, e que pertencem a gerações nascidas até 1980 . Uma vez que para um artista tornar-se conhecido nacionalmente sabemos que incide, na maioria das vezes, o fator tempo de carreira. É importante citá-las porque isso demonstra uma preocupação da curadoria em trazer ao público o que essas mulheres vinham, e vêm realizando, organizadas em termos de linguagens: Ana Lira (1977), com projeto em andamento de pensamentos na forma de site specific; Catarina Dee Jah (1978), com instalação de textos feministas sobre prosaicos panos de prato (fig. 05); Juraci Dórea (1944), instalação; Martha Araújo (1943), registro de performance de seus curiosos "panos-paredes" vestíveis; Sabyne Cavalcanti (1969), performance; Christina Machado (1957), fotografia e vídeos de performance; e Juliana Notari (1975), com sua instigante relação com os testículos de um boi na vídeoperformance apresentada no núcleo Desejo. Virgínia de Medeiros (1973), Ieda Oliveira (1969), Marina de Botas (1975) e Letícia Parente (1930-1991) aparecem na mostra com vídeos. A artista Pêdra Costa (1978), apresentou um conjunto que foi comissionado com diversas linguagens: performance, vídeo, texto e música; Kátia Mesel (1948), publicação; Paula Sampaio (1965), fotografia; Amanda Melo da Mota (1978), desenho e fotografia; Maria Selma (1967), com bordados boa-noite; e Dona Morena (1926), com bonecas de pano preto; Goya Lopes (1954), serigrafia de estampas de temáticas africanas; Guiomar Marinho (1932), tapeçaria; Heloísa Juaçaba (1926-2012), relevos; e Isabela Stampanoni (1975), com pintura e objeto, que foram comissionados pelo Sesc especificamente para esta mostra. A lista realmente é longa e sabemos que convidar artistas que são representadas por galerias para uma exposição é muito mais fácil do que percorrer museus e centros culturais atrás de trabalhos de artistas não tão conhecidas.

É importante frisar que os curadores viajaram até as nove capitais nordestinas e também algumas cidades localizadas no interior, entre agosto de 2018 e janeiro de 2019, para comporem a exposição. No entanto, essas viagens demonstraram regiões mobilizadas por suas reivindicações, durante e após as eleições. Segue trecho que Diniz explica esse processo para a Revista Arte!Brasileiros:

Iniciamos essas viagens e visitas a campo no segundo semestre do último ano, em pleno processo eleitoral. Neste período, o Nordeste vivenciou um momento um tanto quanto singular, revigorante, de contraposição a uma ideia de Brasil que acabou prevalecendo naquele contexto (À Nordeste..., 2020).

A extensa pesquisa de campo trouxe à exposição um volume considerável de trabalhos de artistas que geralmente não têm suas obras circulando em galerias ou museus. Isso gerou a inclusão de diversos mestres que participaram da mostra com suas carrancas, seres místicos, representação de animais nativos, e cenas da vida cotidiana, 


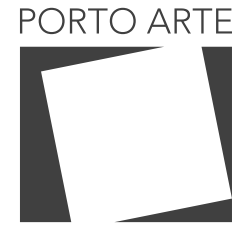

Revista de Artes Visuais

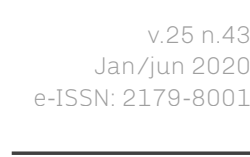

Figura 5: Catarina Dee Jah, Catarina Jah! (2019), técnica mista. Exposição "À nordeste". Foto: Arquivo da autora. entre outros temas que estavam presentes em diferentes núcleos da mostra. Se Mestre Didi (1917-2013) e Mestre Vitalino (1909-1963) já são reconhecidos por sua produção, outros que apareceram na mostra, e até aqueles que nem utilizam esse título, como Véio (1947), formaram um grupo numeroso e semelhante em termos de trajetórias de vida. Geralmente são artistas autodidatas e que se dedicaram à arte por mais de 20 anos.

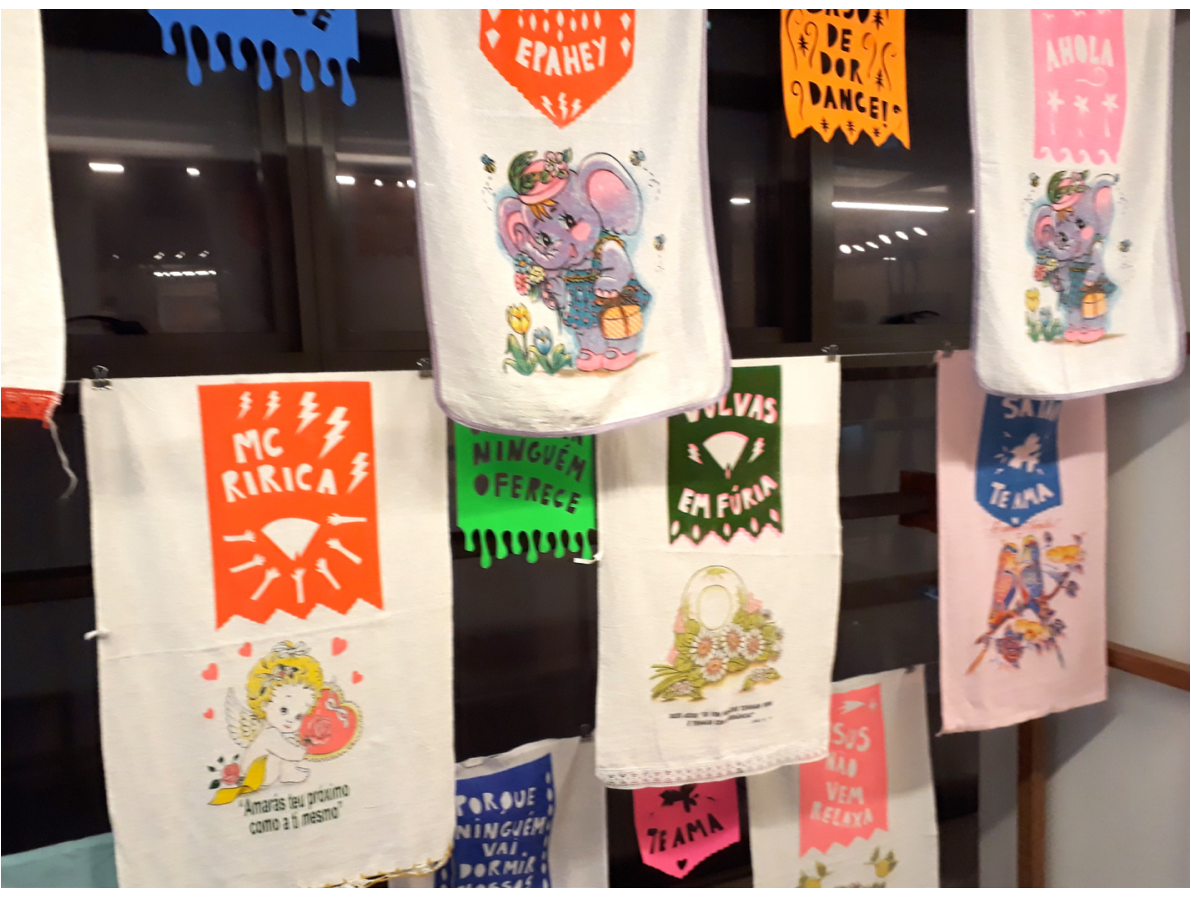

Aspectos estes que, por exemplo, a Secretaria de Cultura de Alagoas define como sendo característicos de um "mestre", ou seja, aquela pessoa que detém um saber e técnicas necessárias para preservar uma manifestação da cultura local, e por isso, eles podem ser beneficiados com um salário-mínimo e meio mensal (Machado, 2020). Iniciativas dessa natureza deveriam ocorrer mais, porque a experiência que esses artistas desenvolveram ao longo dos anos e as alternativas frente a precariedade de instrumentos profissionais merece ser valorizada.

O curioso é que entre tantos mestres os curadores incluíram também uma "mestra" nascida em Alagoas e que é conhecida por suas cerâmicas com cabeças de pessoas negras. Mestra Irinéia (1949) vive da arte desde os 20 anos e resiste em uma comunidade quilombola. Sua matéria-prima vem do barro do chão e seu forno é aquecido pela madeira queimada (Machado, 2020). A ceramista sustenta sua família com a produção artística e ainda, eventualmente, recebe algum reconhecimento internacional por meio de indicação a prêmios. Isso aponta para um estar "a nordeste" neste País, e que se reflete também na situação de tantos outros artistas em diversos estados brasileiros que conseguem viver da arte mesmo em situações adversas, porque acreditam na sua importância, tanto quanto precisam da arte para diminuir os momentos desagradáveis que passam, seguindo o pensamento de Mestra Irinéia (Machado, 2020). 


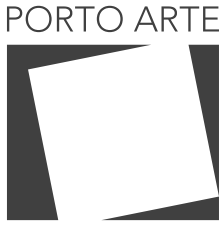

Revista de Artes Visuais

v. 25 ก. 43

Jan/jun 2020 e-ISSN: 2179-8001

Esse movimento de apresentar a produção desses artistas considerados populares é importante porque traz discussões para o sistema da arte sobre como lidar com aqueles artistas que dedicam uma vida a sua produção, mas que permanecem à margem do circuito da arte, muitas vezes relegados ao rótulo de artesãos ${ }^{10}$, para usar um termo de Bulhões (2014, p. 15-16), permanecendo assim em outra categoria da história da arte. $O$ que eventualmente acontece é que algum historiador, crítico ou galerista tem contato com o trabalho desses artistas e credita à produção deles o "rótulo de arte", afastando-a do termo "artesanato" e promovendo-a a ter um prestígio maior até do que "arte popular". Caso semelhante pode ser descrito com Arthur Bispo do Rosário (19111989), que estava presente na exposição com seu Manto da apresentação [entre 1938 e 1988], e que já teve muitas de suas obras apresentadas em bienais e exposições internacionais, principalmente após seu falecimento. Enfim, uma discussão que rende diversos desdobramentos e que merece atenção porque traz para dentro da arte contemporânea a condição de ouvir vozes plurais pois nem sempre há espaço a esses artistas para apresentarem sua produção nos locais mais consagrados. Marcelo Campos comenta a seguir em reportagem na Revista e online sobre a presença desses artistas chamados de populares na exposição:

Temos justapostos artistas renomados e criadores culturais que sequer estão inseridos no circuito que hoje entende-se como o circuito da arte contemporânea. Não hierarquizamos aqui as diversas formas de produção de cultura, como outrora se fez entre "cultura erudita" e "cultura de massa". Esse conjunto cumpre um desejo que é dizer o que é a região hoje e quais são as questões ali em voga. A exposição é muito mais sobre a presença de uma produção do agora e sua potência criativa (Reflexão..., 2020).

Ainda sobre esse aspecto, a curadoria de Jean-Hubert Martin (1944) para "Magiciens de la Terre" (1989), que ocorreu no Centro Georges Pompidou e grande Halle de La Villette, em Paris (FR) (Magie..., 2020), foi fundamental para dinamizar esses debates com propriedade, porque colocou no mesmo patamar expositivo trabalhos de artistas contemporâneos do eixo Europa-EUA, como Barbara Kruger (1945), John Baldessari (1931-2020) e Christian Boltanski (1944), com artistas que viviam nas periferias globais e também locais, a exemplo de Mestre Didi em Salvador, Ester Mahlangu (1935) em uma província da África do Sul e Bodys Isek Kingelez (1948-2015) na República Democrática do Congo. Sem dúvida, um conceito de curadoria ousado para a época e uma atitude necessária, pois houve uma repercussão positiva a respeito da produção desses artistas não só nas regiões onde viviam como também eles passaram a

10- Me refiro a estes "rótulos" porque é comum o mercado da arte definir quem são os artistas e quem são os artesãos. Os valores negociados em galerias para os trabalhos de uns e de outros são substancialmente diferente. Basta comparar o preço alcançado por gravuras de um jovem artista contemporâneo com as xilogravuras de J. Borges, por exemplo, mesmo que tenham dimensões e tiragens iguais, os valores podem ser muito discrepantes. 


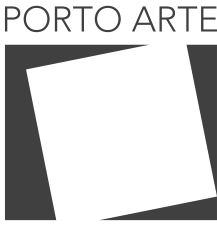

Revista de Artes Visuais

$\vee 25 n .43$

Jan/jun 2020 e-ISSN: 2179-8001

ter reconhecimento internacional que, provavelmente, não teriam tido sem esse atrito proposital da curadoria de Martin.

"À Nordeste" talvez não fosse uma única exposição, mas muitas exposições concentradas no mesmo espaço. Situação semelhante ao que ocorre nas bienais com mostras ou núcleos de temáticas específicas que necessitam de diversas visitas para uma compreensão mais ampla. Ao todo, foram propostos oito segmentos que eram apresentados na forma de textos próximos aos trabalhos: Futuro, Insurgência, (De) Colonialidade, Trabalho, Natureza, Cidade, Desejo e Linguagem. No catálogo, alguns destes textos foram complementados por palavras-chave: Carrancas, Candomblé, Soldados da borracha, Bordado boa-noite, Poema/processo, 0 manto da apresentação, Flagelados da seca, Ratos e urubus, Jangadeiros, Quilombos e Reggae, que apresentavam uma explicação curta sobre alguns dos artistas participantes. Além disso, foram acrescentadas nove colaborações de textos de artistas, professores e pesquisadores em arte, que ajudaram a tensionar alguns dos temas apresentados.

O que se observa é que o volume tanto de obras quanto de textos organizados nesta curadoria foi decorrente de uma vasta pesquisa teórica, já que a exposição vinha sendo pensada há quase dez anos (Rkain, 2020), mas acima de tudo, o resultado desse processo foi relevante para aquele momento histórico. A exposição se posicionou como uma resposta crítica aos ataques direcionados aos nordestinos, inclusive aqueles que vivem em outros estados brasileiros. Mais do que uma resposta, o que a exposição trouxe foi uma lente de aumento sobre muitas questões que ainda precisam ser refletidas e discutidas no País e que não são exclusivas de um único lugar ou região geográfica, mas que dizem respeito aos processos de marginalização de culturas, modos de ser e manifestações artísticas não hegemônicas.

Ainda quanto a esta questão, houve uma preocupação do Sesc em propor uma ampliação da acessibilidade à exposição, que contava com audiodescrição, videoguia em Libras, recursos táteis, pranchas de comunicação alternativa e impressão dos textos com leitura em português ampliado e também em Braille (Outras..., 2019), aspectos inclusivos necessários e que nem sempre estão presentes nas exposições.

\section{Uma crítica}

Em julho de 2019, Amaral publicou na Revista Arte!Brasileiros uma crítica sobre a exposição "À Nordeste" com o título "Uma curadoria". Começando e terminando com a mesma frase: "Uma curadoria não é tarefa fácil de ser concebida", e mais adiante ela escreve: "Talvez esta mostra se configure antes como não se deve fazer uma exposição (e não poderia ter sido dividida em etapas de acordo com a diversidade de linguagens?)" (Amaral, 2020). 0 que se percebe é que o texto crítico não analisou nem a diversidade de trabalhos apresentados nem a complexidade da exposição.

No entanto, é curioso pensar que, sendo curadora da mostra "Além fronteiras", Amaral poderia ter explorado questões já anteriormente lançadas por ela mesma, quanto aos possíveis diálogos e anacronias da relação espaço-temporal na curadoria, que muitas vezes ultrapassam o sentido de analogia de linguagens. Ao contrário, ela se 


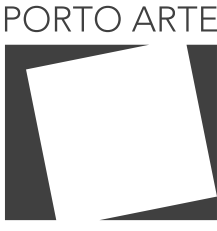

Revista de Artes Visuais

$\vee 25 n .43$

Jan/jun 2020 e-ISSN: 2179-8001

deteve em comentar sobre a montagem, ou melhor, o projeto expográfico, definindo-o como confuso e "labiríntico" (Amaral, 2020), e, além disso, avaliar negativamente o número excessivo de trabalhos apresentados que, de acordo com ela, dificultavam o olhar nesta ou naquela obra. Aspectos que também precisam ser considerados em qualquer curadoria, mas que não excluem outras questões relevantes sequer citadas no texto.

Propor ainda que "À Nordeste" seguisse o modelo expositivo de analogia por linguagens é voltar ao tempo em que essas decisões foram necessárias para situar o aparecimento da arte contemporânea sendo exposta nas grandes mostras ao lado da arte moderna, a exemplo do que ocorreu na $16^{\text {a }}$ Bienal de São Paulo (1981), com curadoria geral de Walter Zanini (1925-2013). No caso da exposição de 2019, não faria mais sentido aplicar esse modelo, porque a exposição já tinha seus próprios núcleos investigativos separados por temáticas. Talvez, um pano de prato esteja mais perto de um meme rodando no celular de "cozinheiras(os)" do que de um programa na televisão da sala. Memelito (2019), vídeo do coletivo saquinhodelixo (2018), estava exposto quase em frente a instalação com utensílios domésticos Catarina Jah! (2019) da artista de mesmo nome.

Os três parágrafos de Amaral não constituem em si uma crítica jornalística, mas funcionam mais como um comentário adjetivado. Uma crítica de arte precisa levantar e discriminar o que se passa no espaço expositivo, seja em galerias, museus, espaços culturais, bienais ou nas ruas. Propor relações entre as obras dos(as) artistas participantes. Discutir o texto curatorial e analisar se os objetivos foram atendidos, ultrapassados ou até se nem chegaram próximo de serem alcançados. Sempre que possível trazer aportes teóricos para ampliar o debate e elencar não apenas os aspectos negativos, mas também os positivos. Assim como a curadoria precisa informar algo ao público visitante, uma crítica também precisa agregar conhecimentos para que o leitor "saia" do texto com mais conteúdo do que quando "entrou" nele. Chegamos a conclusão que uma crítica bem fundamentada pode ser tão difícil de ser redigida quanto o texto crítico de uma curadoria.

\section{Considerações finais}

É inegável que ambas as exposições trouxeram formatações inusitadas para a exibição de trabalhos de artistas, peças ou artefatos históricos, privilegiando muito mais o anacronismo do que uma organização visual cronológica ou centrada em um único recorte temporal. A verdade é que vivemos inseridos em um tempo que assume épocas distintas. É como andar de carro e ultrapassar uma Kombi bicolor e, logo depois, ser ultrapassado por um carro híbrido, para ao final todos sermos ultrapassados por uma carroça que avança rápido sobre o mato rasteiro do acostamento em pleno congestionamento.

Não estranhamos quando aquilo que é antigo, moderno ou atual divide espaço nas cidades, mas muitos ainda estranham que arte contemporânea seja apresentada junto à arte popular ou com a arte produzida por povos originários, artefatos milenares com peças de design, e assim por diante. Nesse sentido, as duas exposições estão muito mais próximas do que distantes, pois ambas não estabelecem limites precisos quanto ao recorte temporal e proporcionam que o visitante olhe uma série de trabalhos 


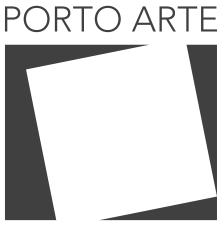

Revista de Artes Visuais

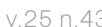

Jan/jun 2020 e-ISSN: 2179-8001

recentes ao lado de outros milenares, como, por exemplo, os vídeos realizados por Camargo, em 2011, ao lado de zoólitos milenares. Não estariam aqueles zoólitos expostos dentro de um museu com arquitetura neoclássica do século XIX no lugar errado? Ou eles deveriam permanecer onde foram encontrados, perto de um sambaqui de difícil acesso (Gaspar, 1999) e ainda correr o risco de serem destruídos por uma retroescavadeira para levantar um condomínio de casas na praia? Sabemos a resposta.

Enquanto "Além fronteiras" abre uma importante discussão quanto ao modo de expor arte dentro da contemporaneidade, e propõe um olhar histórico, "À Nordeste" é uma crítica contundente em formato de curadoria aos processos de legitimação de artistas no sistema da arte, como também é uma crítica às apresentações das exposições contemporâneas, que muitas vezes ainda seguem o modelo expositivo do "cubo branco" no qual o ambiente é neutro, as obras estão corretamente iluminadas e expostas distantes entre si, por vezes distantes até do público e de sua realidade. Ou seja, seguindo uma tradição moderna de expografia.

Chega-se à pergunta: a curadoria não seria sempre crítica? Algumas exposições de fato são explicitamente críticas, constituindo-se como uma discussão ou questionamento aos processos criativos, ao pensamento visual, a fatos históricos, poderes estabelecidos, regimes políticos e econômicos, injustiças sociais, situações relacionadas ao comportamento humano e às questões do campo da arte, mas muitas curadorias se restringem ao papel informativo, apresentando a produção poética de determinado artista, grupo ou movimento artístico, linguagem ou período histórico. Esse objetivo não é menos importante do que o posicionamento crítico, apenas cumpre outro papel, tão relevante quanto dentro da História da Arte.

0 que transcende das duas exposições é que a sociedade brasileira é excludente. Seja porque "Além fronteiras" não trouxe para o centro da discussão os artistas indígenas nem afro-brasileiros para dialogar com os objetos sugeridos pela curadoria; seja porque "À Nordeste" trouxe à tona esses processos de exclusão com diversas facetas. Percebemos que, enquanto uma exposição é excludente, porque não trouxe para o foco da questão os artistas que poderiam falar com propriedade sobre viver na periferia dessas fronteiras políticas, sociais e culturais; a outra é inclusiva, porque convidou artistas negros, indígenas, mulheres, transgêneros e LGBTQIA+, "artesãos" e artistas nordestinos para exporem conjuntamente.

Para encerrar, embora possa parecer estranho para muitos colocar a imensa tela dos Retirantes (1944) de Candido Portinari (1903-1962), artista paulista consagrado do modernismo brasileiro, próximo de um trabalho de Mucambo Nuspano/WG, que a grande maioria dos visitantes nunca ouviu falar, chegamos à conclusão de que a curadoria de "À Nordeste" friccionou o poder legitimador do sistema da arte para que este se torne mais inclusivo.

De certa forma, os curadores da mostra estão dispostos a acelerar esse processo, assim como Jean-Hubert Martin forçou a inclusão de artistas não europeus ou norte-americanos em Magiciens quando convidou artistas de zonas periféricas para exporem seus trabalhos, rituais e culturas ao lado de artistas que, embora jovens, já se encontravam em processo de consagração na arte contemporânea. 


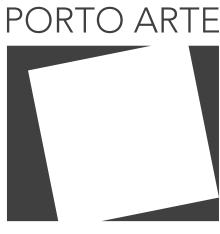

Revista de Artes Visuais

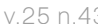

Jan/jun 2020 e-ISSN: 2179-8001

Nem toda exposição de arte contemporânea rompe com a expografia moderna, centrada em ambientes neutros. Assim como nem toda exposição de arte contemporânea tensiona parâmetros cronológicos, mas as curadorias que propõem isso apontam rupturas presentes no modo de ver e sentir a contemporaneidade.

\section{REFERÊNCIAS}

AMARAL, Aracy. Uma crítica. Revista ARTE!BRASILEIROS. Publicado em 2 de julho de 2019. Disponível em: <https://artebrasileiros.com.br/arte/uma-curadoria/>. Acesso em: 8 mar. 2020.

AMARAL, Aracy. Além fronteiras. In: RAMOS, Alexandre Dias (coord.); ROCA, José (curador geral); TALA, Alexia; AMARAL, Aracy; ALVES, Cauê; ALBUQUERQUE, Fernanda; HELGUERA, Pablo; SANTOSCOY, Paola. $8^{a}$ BIENAL do Mercosul: ensaios de geopoética. Catálogo. Porto Alegre: Fundação Bienal do Mercosul, 2011. p. 430 - 481.

À NORDESTE leva 275 obras ao Sesc 24 de Maio: Com curadoria de Bitú Cassundé, Clarissa Diniz e Marcelo Campos, mostra discute o imaginário em torno do nordeste. Redação. Revista Arte!Brasileiros. Publicado em 16 de maio de 2019. Disponível em: <https://artebrasileiros.com.br/arte/a-nordeste-leva-275-obras-ao-sesc-24-de-maio >. Acesso em: 10 jun. 2020.

BULHÕES, Maria Amelia. 0 sistema da arte para mais além de sua simples prática. In: BULHÕES, Maria Amelia (org.) As novas regras do jogo: o sistema de arte no Brasil. Porto Alegre: Zouk Editora, 2014.

CAMPOS, Marcelo; CASSUNDÉ, Bitú; DINIZ, Clarissa (ed.). À NORDESTE. Catálogo. São Paulo: SESC São Paulo Editora, 2019. Disponível em: aplicativo SESC SP. Acesso em: 4 jun. 2020.

CAMARGO, Marina. Tratado de limites. Disponível em: < https://www.marinacamargo. com/portfolio/place-tacuarembo/>. Acesso em: 2 jun. 2020.

CHIARELLI, Tadeu. Apesar de montagem confusa, "À Nordeste" aponta para questões urgentes. Opinião. Revista Arte!Brasileiros. Publicado em 10.07.2019. Disponível em: $<$ https://artebrasileiros.com.br/opiniao/conversa-de-barr/apesar-de-montagem-confusa-a-nordeste-aponta-para-questoes-urgentes/> Acesso em: 8 mar. 2020.

FIRMEZA, Yuri. A nordeste de quê? In: CAMPOS, Marcelo; CASSUNDÉ, Bitú; DINIZ, Clarissa (ed.). À NORDESTE. Catálogo. São Paulo: SESC São Paulo Editora, 2019. Disponível em: aplicativo SESC SP. Acesso em: 4 jun. 2020.

GASPAR, Madu. Sambaqui: arqueologia do litoral brasileiro. Rio de Janeiro: Jorge Zahar, 1999.

MACHADO, Teresa. Agência Alagoas - Governo do Estado de Alagoas. De União dos Palmares: o mundo de barro da artesã Dona Irinéia: Mestra do Patrimônio Vivo é reconhecida internacionalmente. Disponível em: <http://www.agenciaalagoas.al. gov.br/noticia/item/15290-de-uniao-dos-palmares-o-mundo-de-barro-da-artesa-dona-irineia>. Acesso em: 10 jun. 2020.

MAGIE del'art. Magiciens de la Terre. Disponível em: <https://www.magiciensdelaterre. fr/> Acesso em: 15 jun. 2020. 


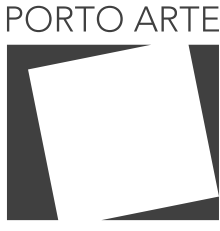

Revista de Artes Visuais

v. 25 ก. 43 Jan/jun 2020 e-ISSN: 2179-8001

MIRANDA, Danilo Santos de. Referenciais deslocados. In: CAMPOS, Marcelo; CASSUNDÉ, Bitú; DINIZ, Clarissa (ed.). À NORDESTE. Catálogo. São Paulo: SESC São Paulo Editora, 2019. Disponível em: aplicativo SESC SP. Acesso em: 4 jun. 2020.

O'DOHERTY, Brian. No interior do cubo branco: a ideologia do espaço da arte. São Paulo: Martins Fontes, 2002.

OUTRAS direções. Revista e. São Paulo: Editora SESC, nº 1, vol. 26, julho 2019, p. 28-33. [artigo não assinado]

REFLEXÃO sobre o Nordeste e o "estar a nordeste" em exposição. Revista e online. Conteudoteca. Publicado em: 12.07.19. Disponível em: <https://www.sescsp.org.br/ online/artigo/13414_REFLEXAO+SOBRE+O+NORDESTE+E+O+ESTAR+A+NORDESTE+EM+EXPOSICAO> Acesso em: 10 jun. 2020. [artigo não assinado]

RKAIN, Jamyle. 275 vezes Nordeste: Exposição "À Nordeste", no SESC 24 de Maio, procura discutir o imaginário acerca do nordeste brasileiro sem folclorização. Revista ARTE!BRASILEIROS. Publicado em: 01.07.19. Disponível em: <https://artebrasileiros.com.br/arte/exposicoes/275-vezes-nordeste/> Acesso em: 10 jun. 2020.

ROCA, José. Geopoéticas. In: RAMOS, Alexandre Dias (coord.); ROCA, José (curador geral); TALA, Alexia; AMARAL, Aracy; ALVES, Cauê; ALBUQUERQUE, Fernanda; HELGUERA, Pablo; SANTOSCOY, Paola. $8^{a}$ Bienal do Mercosul: ensaios de geopoética. Catálogo. Porto Alegre: Fundação Bienal do Mercosul, 2011, p. 41 - 289.

TERREMOTO. Blog. À Nordeste. Disponível em: <https://terremoto.mx/a-nordeste/> Acesso em: 13 jun. 2020. 


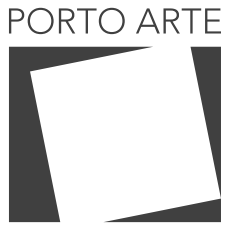

Revista de Artes Visuais

V.25 n. 43

Jan/jun 2020 e-ISSN: 2179-8001

\section{Bettina Rupp}

Doutora em História, Teoria e Crítica de Arte pelo PPGAV da UFRGS. Professora adjunta do curso de Licenciatura em Artes Visuais do Departamento de Artes da UFRN. Atualmente, vice-diretora do Núcleo de Arte e Cultura da UFRN. Coordenadora do projeto de pesquisa Perspectivas em Arte Contemporânea: gênero e invisibilidades e do projeto de extensão Cursos de desenho e pintura do Atelier de Artes do NAC.

Texto recebido em: $15 / 06 / 2020$

Texto publicado em: $30 / 06 / 2020$ 